\title{
CENTROS RELIGIOSOS RURALES MUSULMANES: LAS RÁBITAS DEL VALLE DE LECRÍN
}

\author{
Lorenzo Luis Padilla Mellado*
}

\section{INTRODUCCIÓN}

Es bien conocida la escasez documental que con respecto a al-Andalus poseemos los historiadores medievalistas y en particular la referida a sus tiempos más antiguos.

Aunque podemos advertir sin embargo cierta densidad en el conjunto documental conservado en los Archivos de la Diócesis de Granada, así como de la Real Chancillería que, tras la conquista castellana, en lo relativo a Apeos y Repartimientos de los Bienes Habices que poseían los centros religiosos urbanos y rurales de mezquitas y rábitas, y que tras la expulsión de la población morisca una vez finalizadas las revueltas y levantamientos de la población morisca pasaron en este caso a las iglesias.

Este es un tema que, por lo amplio y desconocido para muchos de los historiadores, conlleva que sólo pueda ser abordado de una manera parcial, estudiando individualmente cada una de las comarcas que eran parte del Reino de Granada.

Existen trabajos realizados por una serie de investigadores como Antonio Malpica, Marçais, Chabbi, Asín Palacios, María Jesús Rubiera, Cristian Picard, Míkel de Epalza, Rafael Azuar, Manuel Espinar y muchos más investigadores que llenan la historiografía en el campo de la investigación del ribāt y rābitas.

La frontera y la práctica del ribāt están íntimamente ligadas. El ribāt es un lugar preferente, aunque no exclusivo, situado en zonas fronterizas y muy relacionado con la idea de la yihad. Así nos lo transmite J. Chabbi ${ }^{1}$, diferenciando entre lo que es el lugar del ribāt y practicar el ribāt. El creyente que practica el ribāt está revestido de un gran coraje, que es una de las cualidades del morabito y la mejor prueba de su piedad.

\footnotetext{
* Universidad de Granada.

1. J. CHAввI, «La fonction du ribát á Bagdad du Ve au début du VIIIe siècle», Revue des études islamiques, 42, 1974, pp. 101-121.
} 
Los rỉbats según Emilio Cabrera, profesor de la Universidad de Córdoba, eran una especie de cuarteles-convento en donde los musulmanes se entrenaban tanto en las practicas ascéticas, como en la preparación de la guerra santa o yihad, y esto debió impulsar a ciertos investigadores en el tema la teoría según la cual las órdenes militares podrían haber sido una derivación del ribāt islámico. Así lo expusieron más tarde igualmente Conde y Oliver Asín. Aunque esto está bastante lejos de la realidad de la misma.

La visión que tenemos en al-Andalus de estos centros religiosos con anterioridad al s. XI es algo confusa. Aceptando la integración de los rībats en el esquema defensivo de la organización militar ${ }^{2}$, la historiografía contempla la posibilidad de que existiera un doble funcionamiento de esta institución: militar y religioso, aunque de los trabajos de estos últimos años podemos deducir que esta teoría pierde fuerza, sin dejar de admitir que en determinados momentos y en casos muy específicos también las rābitas costeras tuvieran un cierto papel militar, y así en sus investigaciones L. Torres Balbás ${ }^{3}$, pudiera haberlas asemejado al ribāț, aunque, como es bien conocido, estas estructuras defensivas y de retiro no suplieron las deficiencias del sistema defensivo costero establecido por el ejercito musulmán.

A partir de los siglos XI y XII se conformará una más profunda alteración en el comportamiento, iniciándose una transformación de las actividades de estos centros fronterizos. Ahora, en los propios enclaves utilizados como ribāț-s se añaden, al deseo militar y ascético, la reflexión en comunidad y la transformación de ideas místicas. Caerán en importancia los ribats y cobrarán mayor importancia las rābitas rurales y proliferarán aún más las urbanas, pero ya como centros religiosos donde los creyentes hacen las plegarias diarias, menos la del viernes que se lleva a cabo en la mezquita mayor o aljama.

La palabra rābita, de la raíz árabe r-b-ț, tiene su origen en las palabras ribāț, rábita y murābiṭ. Morfológicamente significa "lo que ata, vincula, conecta, obliga, refuerza" y posteriormente ha dado lugar a una serie de palabras y múltiples derivados que hay que tener en cuenta para comprender aún mucho mejor el sentido de estas tres palabras, en su doble vertiente de convento fortificado para guardar la frontera y de función religiosa asociada al concepto de Ŷihād o "guerra santa", como nos indica Míkel de Epalza ${ }^{4}$. Es importante aclarar que el ribat servía a la vez para dar la alarma y llamar a rebato, y como un punto de vigía,

2. Personalmente no estoy de acuerdo con esta afirmación para al-Andalus, pues estos centros se ubican en lugares vacíos y son auxiliares del ejército en caso de peligro, no estando incorporados a la organización de la estructura militar.

3. L. Torres BALBÁs, «Rabitas hispanomusulmanas», Al-Ándalus, XIII, 1948, pp. 475-491. Reproducido en Obra dispersa. I Al-Andalus, vol. 4, Madrid, 1981, pp. 157-174.

4. M. de EPALZA, «La espiritualidad militarista del Islam medieval. El ribat, los ribates, las rábitas y los almonastires de Al-Andalus», Boletín de la Asociación española de Estudios Medievales, 3, 1993, pp. 5-18. 
en contacto visual y sonoro con otro cercano, y situado en una posición estratégica. De esta forma se conseguían los dos objetivos perseguidos: primero de valor arquitectónico de la dicha fortificación y en segundo lugar como lugar de práctica religiosa, donde desarrollar la espiritualidad islámica.

De esta forma se podría decir que una rábita sería un edificio de retiro para el espíritu del musulmán, con unas pequeñas celdas o recintos que servían de oratorios, donde se refugiaban los piadosos musulmanes a preparar el espíritu, y que además de realizar sus oraciones también tendrían la obligación de dar la alerta frente a los peligros que pudieran venir del exterior.

No se conocen las vicisitudes históricas por las que pasaron estas edificaciones hasta la conquista de Granada por los Reyes Católicos.

Rábita y ribāṭ han tenido unas relaciones internas muy ligadas. Según María Jesús Rubiera, la rábita tiene un significado de lugar, edificio religioso, pero sin la acepción de fortificación que tiene el ribāț, al que hay que añadirle el significado abstracto de "ejercer la espiritualidad de la guerra religiosa".

Existe también una relación muy destacada entre rábita y al-munastir en el Islam de al-Andalus, según Jaime Oliver Asín 5 las rábitas serían las celdas del munastir. La relación entre rābiṭa y zawiya tiene una aparición más tardía, ambas instituciones conviven en el Reino de Granada (siglos XIII y XIV) ${ }^{6}$. Se podía decir que la rábita todavía hace referencia explícita al deber islámico de la guerra religiosa o ŷihād, y que la zawiya sólo expresa la idea de "retiro espiritual", que es lo que quiere decir su nombre: "rincón retirado".

De todos estos términos podemos concluir que son conceptos religiosos que unen el retiro espiritual y la guerra religiosa. Este equilibrio o dosificación entre estos dos elementos principales es el problema científico y todavía sin resolver adecuadamente.

\section{LOS BIENES HABICES}

Los bienes habices rentaban a la Iglesia cantidades considerables. El régimen en que se otorgan es a perpetuidad y desde el principio, salvando las dificultades iniciales, cada una de las iglesias del reino de Granada procede a tomar posesión de los bienes que les pertenecen.

Los bienes pertenecían a los reyes, los cuales los ceden a la Iglesia; éstos no se pueden arrendar, ni cambiar ni enajenar sin ninguna causa ni razón sin

5. J. Oliver Asín, «Les Tunisiens en Espagne, à travers la toponymie», Les Cahiers de Tunisie, XVIII / 69-70, 1970, pp. 15-20.

6. J. MARTínEZ RUIZ, «Edificios religiosos musulmanes en la Granada morisca», Actas del III Simposio Internacional de Estudios Moriscos. Las prácticas religiosas de los moriscos andaluces (1492-1609), Túnez, 1989, pp. 121-135. 
el permiso de los reyes "y de los reies que después de nos vinieren". Es una ayuda por parte de los reyes para que los cristianos tuvieran el auxilio espiritual necesario.

En las Capitulaciones se les respeta a los vencidos sus instituciones religiosas, pero después de la sublevación los reyes son los dueños de ellos y los ceden a la Iglesia, nobleza y particulares. A partir de 1501 los habices pasan a la Iglesia ${ }^{7}$ pero no será hasta 1506 cuando reciban todas las posesiones anteriormente dadas.

Para tener una relación fehaciente de los bienes se hacen los apeos necesarios, ya que muchos de los bienes en manos de los moriscos y de los cristianos se encontraban perdidos por estar ocultados por aquellos que los tenían a censo.

Los bienes habices fueron una de las instituciones musulmanas que, al culminar la conquista de Granada, es asumida por el poder cristiano, sin apenas llevar a cabo alguna modificación. Aunque éste no es el lugar ni el objeto de estudio en este trabajo, sí me propongo dar unas leves ideas que nos permitan tener una visión más clara de esta institución.

Habiz procede de la palabra habis, que significa "dedicado a un fin piadoso" y da a entender que es consagrar o prometer en voto algo a Dios, "legado piadoso".

El origen sobre estos legados o donaciones piadosas en al-Andalus lo podríamos situar cronológicamente en torno al s. VIII, aunque no será hasta el s. IX cuando existan evidencias documentales contrastadas sobre la existencia de los waqf-donaciones piadosas-, siendo la obra que mejor relata la elaboración jurídica de waqf el tratado del hanafí al-Jassáf (s. IX) ${ }^{8}$ que insiste en tres aspectos esenciales e inherentes a esta institución:

1. Propiedad del bien. El donante debe desprenderse de la propiedad de lo donado, que al fin resulta no ser de nadie. Define al waqf como lo "eterno y perpetuo, que no es propiedad de nadie y no revierte a la propiedad del donante ni a sus herederos". A la cuestión de a quién corresponde la propiedad de un terreno cuyas rentas son donadas por su dueño en su testamento a perpetuidad a favor de los pobres, al-Jassáf insiste en que la propiedad de este terreno no es de nadie y que sus rentas deberán ser entregadas por siempre a los pobres.

2. Carácter perpetuo. La donación debe tener una finalidad perpetua: el waqf es lo permanente y perpetuo, que no es propiedad de nadie y no revierte a la propiedad de su dueño ni de sus herederos. La fórmula "perpetuamente, hasta que lo herede Dios, que es quien heredera los cielos, la tierra y quienes la habitan, pues es el mejor heredero".

7. M.C. Villanueva Rico, Habices de las Mezquitas de la ciudad de Granada y sus alquerías, Madrid, 1961.

8. A. García SAnjuÁn, Hasta que Dios herede la tierra. Los Bienes habices en al-Andalus. S. X al XV, Huelva, 2002. 

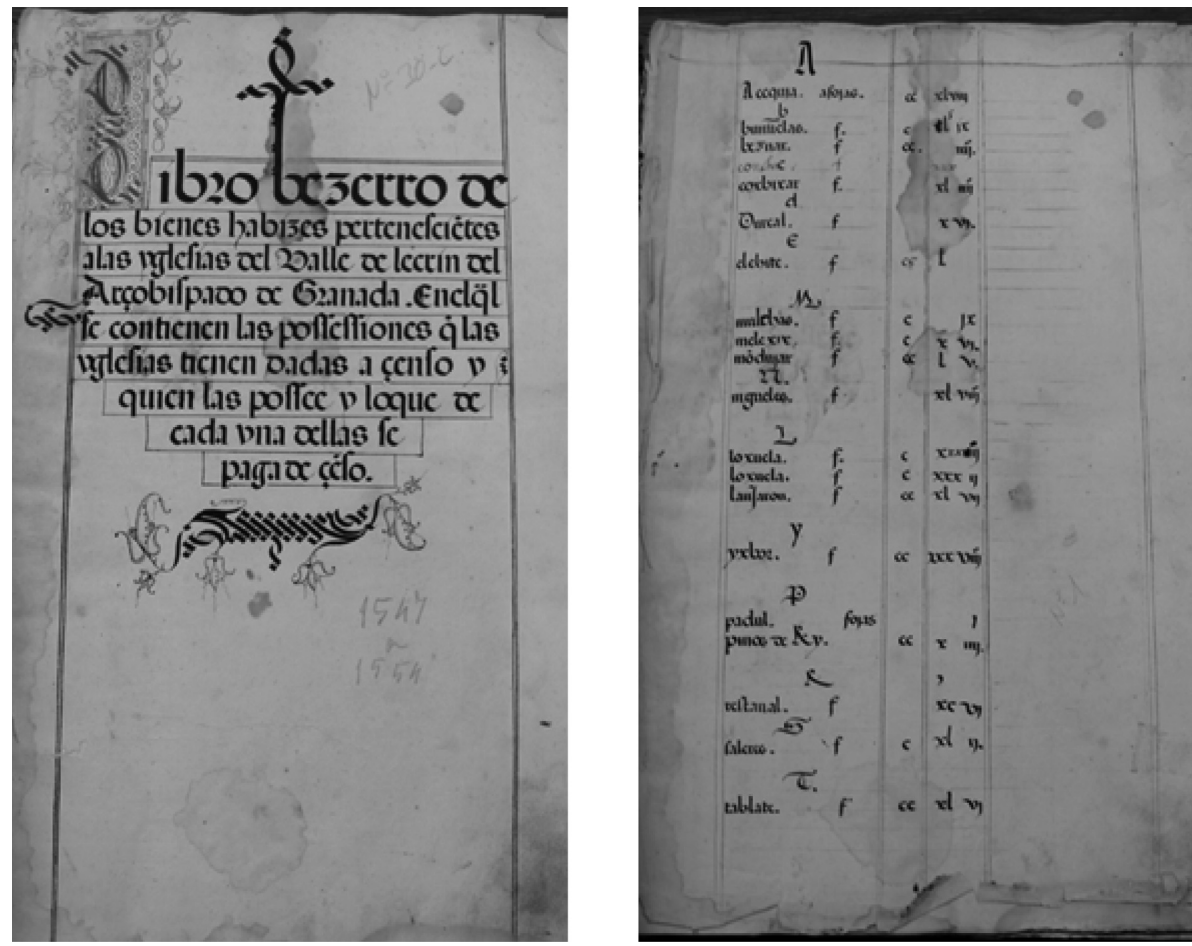

Portada del Libro Becerro de los bienes habices del Valle de Lecrín.

3. Finalidad piadosa. El carácter perpetuo es asegurado y garantizado mediante la presencia en la donación de una finalidad piadosa, expresada mediante el concepto coránico de qurba (Q IX, 99), ya sea en primera o ultima instancia, en caso de donaciones privadas o familiares.

El castellano asumió esta palabra árabe y así la transcribe, utilizándola como un adjetivo, bien = habices o habizes. Esta palabra abarca a todo el conjunto de bienes y rentas dedicados al sostenimiento de mezquitas, madrazas, hospitales y otras fundaciones de carácter piadoso, de utilidad pública, de asistencia a pobres o a fundaciones de familia para protección de parientes.

Los habices podían llegar a componerse, en primer lugar, de pequeñas tiendas, almacenes, alhóndigas, casas o pequeñas viviendas. A estos le seguían establecimientos industriales como baños, molinos, prensas de aceite y azúcar, hornos de pan, jabonarías, fábricas de papel, almadrabas de hacer teja y ladrillo, etc. Y por último llegaban a estar compuestas de explotaciones agrícolas: jardines, heredades, o incluso podía haber hasta pueblos enteros. 
En el Reino de Granada estos bienes llegaron a alcanzar un volumen bastante considerable, cosa que fácilmente se puede comprobar analizando los distintos trabajos realizados sobre los llamados Libros de habices.

Después de la conquista los Reyes Católicos no cambian su condición de legados píos; sin embargo, se aplicarán al sostenimiento de fábricas de iglesias, sacristanías y beneficios. Así lo ordena una carta de 14 de octubre de 1501, en Granada, dada por los Reyes Católicos donde disponen: "Que sus Altezas dan ciertas rentas de los avizes a las yglesias del Reyno de Granada. Y porque para el servicio del culto divino y doctrina de los fieles christianos y porque aya quien los administre los oficios divinos y sanctos sacramentos y los ynstruian e ynformen en las cosas de nuestra fee, avemos acordado que en la çibdad de Granada y en las çibdades, villas y lugares y alcarias de su arçobispado aya algunas yglesias colegiales y parrochiales y en ellas çierto numero de beneficios, segund lo hordenare de nuestro consentimiento el Reverendisimo in Christo Padre Cardenal de Spaña, arçobispo de Sevilla, por virtud de una bula apostolica a nuestra suplicacion ganada a el dirigida para eregir y criar las dichas yglesias y beneficios. Y porque la parte de los diezmos que pertenesçen o pueden pertenesçer a las dichas yglesias no bastan para sustentacion de los dichos beneficiados y sacristanes y para la fabrica de las dichas iglesias, y porques razón que de lo que por graçia de Nuestro Señor ganamos demos alguna parte a las dichas yglesias para que las personas que las han de servir tengan mejor con que se sostener y mantener, y no tengan razón de ocuparse en otras cosas por falta de mantenimiento, y porque tengan cargo de rogar a Dios por nuestras vidas y reales estados y por nuestras animas, quando deste mundo partiéremos, y de los reyes que después de nos subçedieren en nuestros reynos y por las animas de los christianos que murieron en la conquista del dicho reino, por ende, por esta nuestra carta, con el dicho cargo, de nuestro propio motu y cierta çiençia, fazemos gracia y donación pura, perfecta y no revocable ques dicha entre bibos, para agora y para sienpre jamas, a las dichas iglesias collegiales y perrochiales de la dicha çibdad y arçobispado de Granada, para el dote de los dichos beneficios y sacristanias y fabricas, do se puedan mantener los dichos beneficiados y sacristanes de las dichas yglesias y reparar las dichas fabricas, de todas y qualesquier posesiones, bienes muebles y raizes, de la parte de los avizes que en tiempo de los moros estavan dotados y apropiados y pertenescian a las fabricas, alfaquies, almuedanos y otros qualesquier servidores, azeite y çera, y otro qualquier servicio de todas y qualesquier meschitas que solía aver en tiempo moros en la dicha çibdad de Granada y en las otras çibdades, villas y lugares y alcarias, de su arçobispado..."

Los habices granadinos estaban integrados por posesiones urbanas y rústicas. Las primeras podían ser tiendas, grupos de viviendas en sus diversas varie-

9. J. García Oro, La Iglesia en el Reino de Granada durante el siglo XVI, Granada, 2005. 
dades de casas, macerías ${ }^{10}$ y algorfas ${ }^{11}$, o bien hornos, alholíes ${ }^{12}$ y tarbeas $^{13}$, etc. A ellas se unían antiguas rábitas, gimas e incluso mezquitas, cuyas denominaciones se confunden en los libros de habices, especialmente las de rābita y gima ${ }^{14}$.

Las fincas rústicas abarcan una multitud de pagos, hazas, viñas, etc., en la Vega y Sierra. Todas estas posesiones se encomendaban a particulares mediante el pago de una renta anual y que generalmente era en dinero, aunque en bastantes casos iba acompañada de la entrega de una o más gallinas, que en ocasiones podía ser sustituida por perdices.

La Iglesia dedica gran atención a estos bienes, más en los primeros años posteriores a la conquista, con la confusión que lleva consigo el acomodarse del tipo de vida musulmana, al modo de vivir de la sociedad cristiana, y esto unido a la desaprensión de muchos de los arrendatarios -moriscos en su mayoría-, se produce una desorganización de los mismos, que hace necesaria la intervención jurídica, ordenada por los poderes reales. En consecuencia, se realiza una detallada inspección junto a todos los poseedores de bienes habices.

Fruto de esta detallada inspección es una minuciosa relación de las posesiones, en la que se llega a fijar no sólo el emplazamiento y número de habitaciones de una vivienda, sino también las dimensiones de cada una de ellas, nombre y oficio de su morador, renta que paga y vecinos colindantes.

Si esto es en las fincas urbanas, en las rústicas hasta se especifica el número y especie de los árboles frutales $\mathrm{y}$, si se trata de morales, la cantidad de simiente de gusanos de seda que pueden alimentar, como el nombre del pago, situación, calidad: de secano, viña, huerta, etc. El compendio de toda esta información constituyeron los Libros de habices.

\section{ORGANIZACIÓN ECLESIÁSTICA DEL VALLE DE LECRÍN}

Bula de erección de las iglesias del Valle:

Erige las Yglesias del Valle ${ }^{15}$.

10. Al-macería: habitación única, especie de cámara de un piso alto, cuyo bajo lo ocupa generalmente una tienda o taller.

11. Algorfa: en oriente se daba este nombre a la almacería, pero en sentido más amplio, ya que podía tener varias habitaciones.

12. Alholíes: granero, almacén de sal.

13. Sala grande, cuadrada.

14. Este nombre se daba a la mezquita donde se hacía la oración oficial del viernes. En cada ciudad había sólo una de estas mezquitas, pero será a partir del s. VIII cuando se extienda esta denominación a toda mezquita de cierta importancia, y así llegan a multiplicarse en número en las ciudades. Por otra parte a los santuarios pequeños o de menos importancia se les llamaba simplemente mezquitas.

15. Escrito en el margen izquierdo del manuscrito y fuera de la caja de escritura. 
Et in taha de Valdelecrin in ecclesia parochiali Sancta Mariae loci de Arrastaual cum suis annexis de Melexis, Amulchas, Alauxa, Barmelaz, Naio, Saleris et Cautil, locorum Granatensis diócesis, quatuor benefitia simplitia seruitoria et quatuor sacristias. In ecclesia parochiali Sanctae Mariae loci de Veznar cum suis annexis de Tablate, Pinos de Rey, Yzbur, Atalarat, Mondujar, Acequia et Achite, locorum Granatensis diócesis, tria simplitia seruitoria benefitia et tres sacristias. In ecclesia parochiali Sanctae Mariae loci de Padul cum suis annexis de Concha, Coxbixar, Durcal et Nigueles, locorurn Granatensis diócesis, tria benefitia simplitia seruitoria et tres sacristias. In ecclesia parochiali Sanctae Mariae loci de Najaronsepe dictae Granatensis diócesis, duo benefitia simplitia seruitoria et duas sacristias, auctoritate apostolica praedicta qua fungimur in hac parte de regis et reginae, dominorum nostrorurn patronorum instantia et petitione tenore praesentium (ut praefertur) creamus et instituimus.

La traducción es la siguiente:

"Y en la Taha de Valdelecrín ${ }^{16}$ en iglesia parroquial de Santa María del lugar Arrastaual ${ }^{17}$ de Restábal con sus anejos de Melexís ${ }^{18}$, Amulchas ${ }^{19}$, Alauxa ${ }^{20}$, Bermelaz $^{21}$, Naio ${ }^{22}$, Saleris ${ }^{23}$ y Cautil ${ }^{24}$, de los lugares de la diócesis de Granada, cuatro beneficios simples servideros y cuatro sacristías. En iglesia parroquial de Santa María del lugar de Veznar ${ }^{25}$ con sus anejos de Tablate, Pinos del Rey ${ }^{26}$, Yzbur $^{27}$, Atalarat ${ }^{28}$, Mondújar, Acequia ${ }^{29}$ y Achite $^{30}$, lugares de la diócesis de Granada, tres beneficios simples servideros y tres sacristías. En iglesia parroquial de Santa María del lugar de Padul con sus anejos de Concha ${ }^{31}$, Coxzbixar ${ }^{32}$, Durcal y Nigueles ${ }^{33}$, lugares de la diócesis de Granada, tres beneficios simples servideros y tres sacristías. En iglesia parroquial de Santa María del lugar de Najaronsepe $^{34}$ de esta dicha diócesis de Granada, dos beneficios simples servideros

\footnotetext{
16. En la actualidad Valle de Lecrín.

17. En la actualidad Restábal.

18. En la actualidad Melegís.

19. En la actualidad Murchas.

20. En la actualidad Lojuela.

21. En la actualidad se desconoce su situación.

22. En la actualidad se desconoce su situación.

23. En la actualidad Saleres.

24. En la actualidad se desconoce su situación.

25. En la actualidad Béznar.

26. En la actualidad Pinos del Valle.

27. En la actualidad Ízbor.

28. En la actualidad Talara.

29. En la actualidad Acequias.

30. En la actualidad Chite.

31. En la actualidad Conchar.

32. En la actualidad Cozvijar.

33. En la actualidad Nigüelas.

34. En la actualidad Lanjarón.
} 
y dos sacristías, las cuales creamos en estos lugares por autoridad apostólica del rey y reina a instancia y petición de nuestros señores patronos creamos e instituimos (como ya se ha dicho) ante el tenor presente".

Los actuales municipios que componen la comarca del Valle de Lecrín son los siguientes:

Acequias, Albuñuelas, Béznar, Conchar, Cozvíjar, Chite, Dúrcal, Ízbor, Melegís, Mondújar, Murchas, Nigüelas, El Padul, Pinos del Valle (o del Rey), Restábal, Saleres, Tablate y Talará. Respecto a Lanjarón no es integrante del Valle de Lecrín, pues queda a caballo entre este partido y la Alpujarra. En este trabajo lo estudiamos como población del valle de máxima importancia, dado el papel que ha desempeñado, tanto comercial, como militar y además como zona de paso entre la costa, la Alpujarra y Granada.

El paso de las tierras que componían el Reino de Granada a la corona castellana llevaba implícitos muchos problemas de organización política, militar, económicos y religiosos que los reyes trataron de arreglar rodeándose de eficaces colaboradores. La conquista del Reino de Granada pone en relación a dos comunidades: vencedores y vencidos, que tienen diferentes modos de vida. Las capitulaciones y pactos firmados entre musulmanes y cristianos eran la garantía para que todos siguieran viviendo sobre las tierras. Pronto este espíritu de convivencia se va a ver roto, por lo que se producen las primeras revueltas. Cada día los nuevos pobladores venidos a las tierras del Reino de Granada hacían lo posible para que los mudéjares marcharan a otros lugares de la Península o al norte de África y así poder tener acceso a las propiedades de los que huían por un precio mínimo. Esta actuación fue en muchos casos defendida incluso por la Corona y algunos de sus representantes, como Hernando de Zafra (secretario de los reyes), partidario de una emigración continuada. Estas acciones de los cristianos llevaron a un autor a escribir lo siguiente: "Luego que el rey de los cristianos vio que los musulmanes no emigraban, y por el contrario que se hallaban decididos a permanecer en sus hogares, resolvió romper las capitulaciones, como lo hizo, ... en efecto, cláusula tras cláusula, hasta concluir con todas ellas. Dejó de protegérseles; se les miró con menosprecio y desdén, y tratándoles los cristianos con fueros de dominadores, los sometieron a leyes tiránicas y les recargaron los tributos. Prohibídseles el llamamiento a la oración desde las torres de sus mezquitas y se les expulsó de la ciudad de Granada a los arrabales y alquerías, a donde se retrajeron envilecidos y afrentados. Tras de esto, y por el año 904 (1498-1499) se les invitó a abrazar el cristianismo, como así lo hicieron, cediendo a la violencia. Toda la Andalucía se hizo cristiana, hasta el punto de no quedar en ella quien dijere: «no hay más Dios que Dios, Mahoma es el enviado de Dios», como no lo dijera en su corazón o a ocultas de las gentes" ${ }^{35}$.

35. F. de P. VAlladAR y SERRANO, «Los moriscos granadinos», Revista de La Alhambra, XII, 1909, pp. 343-346. Recoge este testimonio de Eguílaz Yanguas en su obra Reseña histórica de la conquista del reino de Granada, pp. 69-70, quien a su vez traduce la obra titulada Narraciones de la época sobre la extinción de la dinastía nazarita y otros testimonios. 
El deseo de los reyes y parte del clero era que los mudéjares se fueran convirtiendo y asimilando a la sociedad castellana, motivo principal que llevaría a Cisneros a Granada en ayuda de Talavera. Los métodos del arzobispo de Toledo no fueron eficaces en muchos casos, con lo que se llegó al enfrentamiento armado, extendiéndose la guerra a las comarcas de las Alpujarras, Almería, Málaga, antiplanicies de Guadix-Baza-Huéscar y río Almanzora, teniendo que intervenir el rey en persona y sus mejores hombres de armas relacionados con el nuevo reino incorporado a la corona.

Sofocadas las rebeliones y sucesivas revueltas que se produjeron a lo largo del s. XVI, se procedió a la confiscación de bienes, no sólo de los sublevados, sino de todos los moriscos. Las nuevas autoridades cristianas reordenaron el Valle de Lecrín en tres grandes parroquias, que se corresponden con las zonas baja, media y alta de la comarca, según se aprecia en la bula de erección del arzobispado de Granada:

- Restábal, con sus anejos de Melexis, Murchas, Alauxa, Burnielas, Naro, Saleres y el Cautil.

- Béznar, con los anejos de Tablate, Monduxar, Azequias y Achite.

- Padul, incluyendo a Cónchar, Cozvíjar, Dúrcal y Nigüelas.

\section{LAS RÁBITAS DEL VALLE DE LECRÍN}

Son múltiples los lugares de rábita que se citan en los diferentes documentos que se han estudiado en el Archivo Histórico del Arzobispado de Granada ${ }^{36}$, ya sea por el Libro Becerro de los Censos que se pagaban a las iglesias del valle de los años 1547-1554, conservado en el AHAGr., con Signatura Caja $\mathrm{n}^{\circ} 44$, así como las diferentes escrituras de censo relativas a los habices de las iglesias del Valle de Lecrín ${ }^{37}$, donde se detallan su situación, linderos, en algunos casos su superficie, qué personas las poseían a censo, qué aprovechamiento se había hecho de los solares donde se ubicaban éstas, algunas convertidas en casas, otras en huertos y en muchos casos como hazas de riego.

A continuación se van a relacionar siguiendo el orden alfabético los núcleos de población que conforman el Valle de Lecrín, la denominación de las diferentes rábitas, que en dichos documentos se especifican, con expresión del documento y número de folio en que viene citada, su situación y quién lo tenía a censo, etc.

36. En adelante AHAGr.

37. L.L. Padilla Mellado, Los Habices de las Iglesias del Valle de Lecrín. Historia y Arqueología, Tesis doctoral presentada en la Universidad de Granada (2010) y dirigida por el profesor Manuel Espinar Moreno. 


\section{Acequias}

En el Libro Becerro de los Censos que se pagaban a las iglesias del valle ${ }^{38}$, no se especifica ninguno de estos centros religiosos. Sí encontramos en una escritura que se conserva en el AHAGr., de fecha 31 de octubre de 1592, que se hace ante el escribano del rey Alonso de Solís: "una rābita, dos plazuelas y medio marjal de tierra ${ }^{39}$, con 5 matas de morales nuevos y 1 higuera, que tiene a censo Pedro Álvarez. Alinda con un horno y una tienda de Diego Maldonado, vecino de este lugar, y por otra con calle y camino que va del lugar alto al bajo". Se relaciona un sitio de rābita, 1 moral y 1 higuera, por bajo tiene un pedazo de macaber de medio marjal. La higuera no es de la iglesia. Alinda lo uno con lo otro y su solar es linde por una parte con tierras y por otra con dos acequias. En este macaber estaba un moral "que no hay memoria de él".

\section{Albuñuelas}

En este lugar sí existen muchos más restos de estos centros religiosos que lo que se ha especificado para Acequias y que se irán repitiendo en todos los diferentes documentos que se han estudiado, resaltando y ratificando con pequeñas connotaciones y diferencias cómo en cada uno de los barrios en que se distribuía la población había uno de estos centros religiosos, además de la mezquita principal.

En el Apeo y Deslinde de los Bienes de la Iglesia de las Albuñuelas ${ }^{40}$ que se conserva en el Archivo de la Real Chancillería ${ }^{41}$, con Signatura 5417-15, se relaciona una casa que se labró en la rábita de Najo, situada en el Barrio Bajo del lugar, la cual se midió y tuvo 40 pies $^{42}$ en largo y en ancho 22 pies. "Tiene a la entrada de la dicha casa un portal encamarado y luego un patio y a la mano izquierda del dicho patio una caballeriza encamarada de dos suelos y luego dentro de la caballeriza un establillo encamarado. Alinda dicha cassa con casa de Lorenzo de Vélez, con un horno y con haza de Lucas Azara. Un haza de riego con el agua que le pertenece de 1,5 marjales, poco más o menos con 1 higuera que es de la Rábita de Nazir. Linde de haza de Hernando Mudayal, con haza de Francisco Juadali y con dos caminos".

En el Barrio de Jaulila o Ajeulil también se inserta un solar de rábita que se llama Ajeulil, con un macaber junto con ella de 3 marjales poco más o menos, que alinda con unas peñas y un camino.

\footnotetext{
38. En adelante Libro Becerro.

39. 1 marjal $=525 \mathrm{~m}^{2}$.

40. ARCh. Signatura 5417-15.

41. En adelante ARCh.

42. 1 pie $=0,29 \mathrm{~m}$.
} 
También podría haber existido una mezquita, pues aunque no se cita como tal sí se detallan bienes habices de ella como así lo relaciona el escribano cuando detalla "un haza en 2 pedazos que la parte un jorfe por medio, de riego con el agua que le pertenece de 1,25 marjales, poco más o menos, con 1 almez e higueras, que es de la mezquita, que alinda con el horno susodicho, con el camino por una parte, por otra con haza del Baeni y por las otras partes con otro camino y haza de Antón Galib. Sigue también otro olivo de la mezquita junto a la haza susodicha que cae sobre una acequia de agua y sobre un haza de Antón Galib, el cual tiene un pedazo de macaber de una 1/6 parte de marjal, poco más o menos con un granado".

Igualmente en el pago de Almozen se especifica otro sitio de rábita que está hecho parral, el cual se midió y tuvo 26 pies en largo y 15 en ancho. Alinda con casa de Cristóbal Alheche y con dos calles alrededor. En el Barrio de Cautil se detalla igualmente otro sitio de rābita, que se llamaba la Rābita Harantain, con una torre alta en medio de una plazuela.

Este centro religioso tenía 2 olivos, "el uno en haza de Lorenzo Adunazi y el otro junto a un jorfel de Jorge Uzayas y alinda con el acequia el uno".

En el Libro Becerro se relaciona también un sitio de rábita que se llama de Benefeh con un pedazo de tierra que le pertenece, que puede ser una $1 / 6$ parte de marjal, que alinda con el camino. Un sitio de rābita que tendrá 26 pies en largo y 15 en ancho. Alinda con casas de Cristóbal Alhax y con dos calles alrededor, en ocho maravedís de censo.

Como también relaciona el escribano para el lugar de Albuñuelas un solar de casa con una torre que solía ser rábita, esta se localiza en el Barrio del Conti, que alinda con casa de Pedro Hernández Yacob y con casas de Garçía Aladebez. Igualmente se informa que había una casa que con anterioridad fue una rábita y que fue traspasada por Leonardo Martínez en 5 reales.

\section{Béznar}

En el Libro para el lugar de Béznar se cita una rábita que está en el Barrio Bajo de Béznar, linde de casas de Diego el Boruque. Este sitio de "rābita en una casa de Francisco Yáñez Descovedo, vecino de Granada. Reconoçió por 1,5 reales de censo para pagarlo por principio de octubre de cada un año", según escritura que se hizo ante el escribano público de Granada Diego Diez. Su fecha a 16 de agosto de 1592.

En el Apeo de Béznar que se hizo en $1592^{43}$, se detalla una casa que se dice de la mezquita, en el dicho lugar que está en el Barrio de la Iglesia, linde por una parte con casa de Francisco González, por otra con una calleja que pasa entre la

43. AHAGr. Sign. 585-F. 
Iglesia y la dicha casa, por otra parte con huerto de Lorenzo Vizcaíno y por otra la calle y Camino Real que va desde Granada a las Alpujarras.

También especifica la existencia de un horno de la mezquita con su plazuela delante, que alinda por tres partes con huerta de los hijos y herederos de Gonzalo Delgadillo, por otra con casa de Juan Gómez de Benavente y por delante de ella la calle y Camino que va de Granada a la Alpujarra.

También en una Pieza de Autos ${ }^{44}$ se relaciona una casa que antiguamente llamaron mezquita, y que hoy la poseen Juan de Pedrosa, Paula Pedrosa y Manuel López de Haro, cada uno por su respectiva parte que al presente está dividida en tres. Fue tasada en 1.300 reales. Otra casa en el Barrio de la Rábita, linde con casa del Beneficio y Calle Real, en precio de 4.000 reales.

\section{Cónchar}

En el Libro Becerro se relaciona una casa en el dicho lugar de Cónchar, que alinda con casa de Miguel Pérez y casa de Domingo Pérez y la Calle Real. "Hay así mismo una rābita junto con ella que se llama la Rābita de Harazel. Todo por el dicho precio".

En una de las escrituras de censo que se conservan en el AHAGr. ${ }^{45}$ se informa de que ante el escribano público y notario de sus majestades Alonso Ruiz, de fecha 5 de septiembre de 1547, "por la que Miguel el Nayar, tomó de la iglesia de Cónchar a censo perpetuo de 102 maravedíes, una casa caída, una torre y una rābita juntos en dicho lugar, lindes con Domingo Granig".

\section{Cozvijar}

En este lugar no se especifica en ninguno de los documentos estudiados la existencia de algún centro religioso.

\section{Chite}

En el AHAGr. ${ }^{46}$ se encuentra una Escritura de Reconocimiento de Censo donde Francisco Jijón reconoce un solar de rábita "que solía ser, que está en el dicho lugar, linde con el Barrio Alto, en medio de ambos barrios". Alinda por tres partes con tres caminos de servicio del dicho lugar y el uno de los caminos alinda con la casa de Baltasar Herrera. En otra escritura de censo también se relacionan bienes habices que pertenecían a rábitas del lugar de Chite, como la rábita de Alcudia y la de Alfauquin.

\footnotetext{
44. AHAGr. Sign. 585-F.

45. AHAGr. Sign. 586-F.

46. AHAGr. Sign. 586-F.
} 


\section{Dúrcal}

En el dicho Libro Becerro se relaciona un censo perpetuo de Lorenzo el Marche, el cual pagaba 42,5 maravedís por dicho censo, "pagados por fin de octubre por un solar de casa y un solar de rābita en el Barrio de Azocat".

Ambrosio Alburza Cantarero paga 12 maravedís de censo cada año "por un solar de casa y un solar de una rābita en el Barrio de Balina junto con casas del susodicho". Se hizo carta de ello ante el escribano del rey Alonso Ruiz. Su fecha es de 25 de abril de 1547.

Álvaro de Navas paga 5 maravedís de censo cada año, pagados por fin de octubre, por una casa que le traspasó Francisco el Conis el Mozo, que la labró en un solar de rābita en el Barrio de Abdarro, linde con huerta de la iglesia y con las Calles Reales. Hay carta de traspaso de ella que pasó ante el escribano público de Granada Pedro de Córdoba. Fecha en 15 de abril de 1547. "Y un haza que se dice Fadin Ajual de 3 marjales con un aceitunillo, en el Pago de Almoceta, que alinda con haza de Hernando de Antequera Zolaytas, con haza de Bartolomé Acequia, y fue el remate del Horno en 3 ducados cada año y medio marjal con la rābitilla, en 10 maravedís".

Igualmente en una Pieza de $\mathrm{Apeo}^{47}$ se hace alusión a un haza de 1,5 marjales, en medio de la rábita que llaman de Audaul, en el lugar de Dúrcal. Alinda con haza de Vider, vecino de Nigüelas, con haza de Diego Díaz y con haza de Martín Alborayal.

En el AHAGr. ${ }^{48}$ también se citan algunas rábitas del lugar de Dúrcal. En escritura que se hace ante el escribano público y notario de sus majestades Cristóbal Hurtado de Fuertes, de fecha 22 de septiembre de 1598 por la que Francisco Zamorano tomó de la iglesia de Dúrcal a censo perpetuo de 154 reales y 32 maravedíes, algunos bienes, "estando entre estos 4 bancales que tendrán 10 marjales de tierra con las moredas que tiene dentro en el Pago de la Rābita, linde con Juan Calero y Marcos de Jodar y olivos del Licenciado Malpartida", en el camino de Nigüelas.

Más otra escritura que se hace ante el escribano público y notario de sus majestades Alonso Ruiz, en 25 de abril de 1547 por la que Lorenzo el Atarche tomó de la iglesia de Dúrcal a censo perpetuo "de 42 maravedíes varias hazas y macaberes, un solar de casa y un solar de rābita en dicho pueblo en el Barrio de Azoca".

Otra escritura que se hace ante el mismo escribano Alonso Ruiz, en 25 de abril de 1547 por el que Antonio de Burgos tomó de la iglesia de Dúrcal "a censo perpetuo de 12 maravedíes 2 pedazos de solar de rābita y casa en el Barrio de Balina de dicho pueblo".

47. AHAGr. Sign. 291-F.

48. AHAGr. Sign. 232-F. 
Ízbor

También en el AHAGr. ${ }^{49}$ se conserva una escritura que se hace ante Alonso Ruiz, escribano público y notario de sus majestades, en 22 de septiembre de 1547 por la que Lorenzo el Viejo tomó de la iglesia de Ízbor a censo perpetuo de 148 maravedíes algunos bienes, encontrándose entre estos un olivo de la iglesia de Pinos, que linda con olivos de la iglesia y es en la misma tierra. "Linde con tierras del dicho Andrés de Santillana y un olivo de la mezquita del lugar despoblado de Béznar y las tierras de Güajares y en su sitio de tierra, linde olivos de la iglesia y cae sobre haza del dicho Andrés de Santillana".

\section{Lanjarón}

En el Libro Becerro se hace referencia que Juan Querque de Salazar, vecino de Buñuelas paga 22 reales de censo perpetuo, "pagados por fin de cada un año por un sitio de iglesia vieja [mezquita] y un macaber en el lugar de Lanjarón". Su fecha en 14 de agosto de 1574, según escritura que se hizo ante el escribano público de Granada Francisco de Córdoba.

En las escrituras de censo que se conservan en el AHAGr. ${ }^{50}$ se cita el mismo sitio de iglesia vieja, por una escritura que se hace ante Diego Díaz, escribano público y notario de sus majestades de fecha 14 de agosto de 1564, por la que Juan Quiezqui de Salazar tomó de la iglesia de Lanjarón "a censo perpetuo de 22 reales, el sitio de la Iglesia Vieja del dicho lugar, con las torres, tapias y cimientos y una huertezuela en ella aneja con 1 moral, higueras y otras plantas, linde con la Calle Real, con la acequia que baja del Cenete al Castillo, por la espaldas con el Mesón de Minales y por delante la casa de Animas, con 2 morales uno grande y otro pequeño, linde con el Camino de Granada, con Martín Abolany".

Por otra escritura que se hace ante Diego Díaz, escribano público y notario de sus majestades de fecha 22 de junio de 1530, "Gonzalo Arévalo tomó de la iglesia de Lanjarón a censo perpetuo de 17,5 reales, una haza en que puede haber medio marjal con 8 aceitunos y 4 morales, y una rábita junto a esta haza, linde con el Camino Real y con huerta de Juan de Vega".

"Más un pedazo de tierras que será de un cuarto de marjal poco más o menos que solía ser rábita, con 1 higuera y tiene 1 moral que no es suyo ni de la suerte de la iglesia, que se dio a censo a Francisco de Moya. Alinda con el camino que va a Orjiva y con la calle que va a cassa del dicho Hernando Mateo".

Por otra escritura que se hace ante Pedro de Nabas, escribano público y notario de sus majestades de fecha 10 de agosto, Francisco de Moya y su mujer tomaron de la iglesia de Lanjarón a censo perpetuo de 67 reales varias fincas en

49. AHAGr. Sign. 572-F.

50. AHAGr. Sign. 566-F. 
el lugar y termino de Lanjarón. Entre todos estos bienes se le da a esta suerte "una estaca de moral que está en un pedazo de tierras que solía ser rābita, que es de la dicha iglesia y está en tierra que se le dio a censo a Hernando Mateo. Se le dan más 2 morales que están juntos en el camino que va del Barrio del Azocaque al Zenete, y están en un bancalejo que tiene una rábita que también se le da a esta suerte. Alinda por la parte de arriba con huerta de Pedro de Villaverde y tierra de Juan García de Poza y por la parte de abajo con otro bancal de la iglesia que se le da a la suerte de Esteban Velázquez".

\section{Melegís}

En el Libro Becerro se relaciona un pedazo de mezquita vieja que se llama el Marma con un pedazo de macaber por abrir, que tenía un álamo blanco grande que se cortó para la iglesia, de 1,5 marjales poco más o menos, que alinda con el Camino Real y una alberca de lino.

En las escrituras de censo del AHAGr. ${ }^{51}$ se relaciona en una escritura de reconocimiento que se hace en 21 de agosto de 1565 a favor de la iglesia de Melegís por Alonso el Güajari, "de un censo perpetuo de 429 maravedíes, sobre varios olivos y tierras y entre ellas 2 aceitunos de la Rābita de Albuñuelas, en jorfel de haza de Agustín Magravi, y cae en haza de Domingo el Chite, con el cargo en cada un año de 3 reales de censo perpetuo".

“Un pedazo de mezquita vieja que se llama el Marma, con un pedazo de macaber por abrir, que tenía un álamo grande, que se cortó para los hornos de Nigüelas, en que puede haber 1,5 marjales poco más o menos, que alinda con el Camino Real, con un alberca donde se recoge el agua para regar, con una alberca de lino y con haza y olivar de García López". Este pedazo es el mismo que se ha citado en el Libro Becerro.

Un sitio de rábita que solía ser de un lugar que se decía de Arayali que se perdió, linde con un camino que va a Melegís.

\section{Mondújar}

En el Libro Becerro se inserta "una rabitilla que está enfrente de un mesón situado en Haratalarab, barrio de los árabes [Talara] que alinda con casas del Cadah y Calles Reales". Todo lo cual le traspasó Diego Delgadillo, que de ello tiene Carta de Censo que está en la Contaduría. Y pasó ante el escribano público de Granada Diego Díaz de Valdepeñas, en 22 de diciembre de 1531.

En las escrituras del AHAGr. ${ }^{52}$ de este lugar se da a censo un mesón en la calle donde está un horno, con su corral y huerto, que antiguamente era casa de

51. AHAGr. Sign. 566-F.

52. AHAGr. Sign. 572-F. 
la iglesia. Alinda todo por una parte con huerto de Antonio García, por otra con huerto de Diego de Fuentes, por otra con tierra y árboles de Cristóbal de Tapia, a un lado alinda con casa de Diego de Fuentes, la Calle Real. Frontero de la puerta está un sitio y plazuela que solía ser mezquita, que alinda por la calle que pasa a la puerta del mesón, por la otra arte con el aljibe del agua, por otra con casa y huerto de Francisco García y por la otra con la calle que va a Mondújar desde el dicho mesón.

“Un olivo en un haza que está cercada de piedras en el Camino Real por la parte de abajo y un llano. Está dentro de un haza de medio marjal en el Pago de Contra, que es olivar y alinda con el Camino Real que va del dicho lugar a Béznar y por otra parte el barranco", que es donde antiguamente solía estar una mezquita.

\section{Murchas}

No se ha encontrado ninguno de estos centros religiosos en los documentos que se han estudiado hasta el momento.

\section{Nigüelas}

En el Libro Becerro se relacionan los censos pertenecientes al beneficiado de Nigüelas, Juan de Vilches. Entre estos se relaciona "una rābita por la que paga 6 maravedís de censo cada un año". Alinda con Pedro Alaraz y con Hernando Adulmeli Mendoza. En la carta del censo que tiene de ello hay otras posesiones, las cuales dio Antón Lorenzo y Antón Pariente y en ellas se hizo cargo del censo que falta en la escritura que falta, montando 4 reales. Pasó la dicha escritura ante el escribano público de Granada Pedro de Córdoba. Su fecha en 5 de noviembre de 1540.

"En esta rábita se hizo una casa la cual posee la iglesia y está dada a censo a Nicolás López Pulido y su mujer, vecinos de Nigüelas, con otra casa en el dicho lugar. Linde con casa de Juana de la Paz y otros linderos, en precio de 30 reales, pagados por Santiago de cada un año, según escritura que se hizo ante el escribano público del Valle, Pedro de Nava". Su fecha a 25 de julio de 1593.

El dicho Juan de Vilches paga 29,5 maravedís cada año por otras posesiones, "entre las que se encuentran una rābita que alinda con casa de Lorenzo de Rojas. Otra rābita y un pedazo de era junto a ella que está en las Eras Altas y un pedazo de tierra junto a la huerta de Francisco el Sordo y con casa de Pedro Zale. Y en ella está una casa que el dicho Juan de Vilches traspaso y la tiene Alonso Arrioli. Paso la carta del dicho Juan de Vilches ante el escribano público Pedro de Córdoba". Su fecha en 17 de febrero de 1540. 

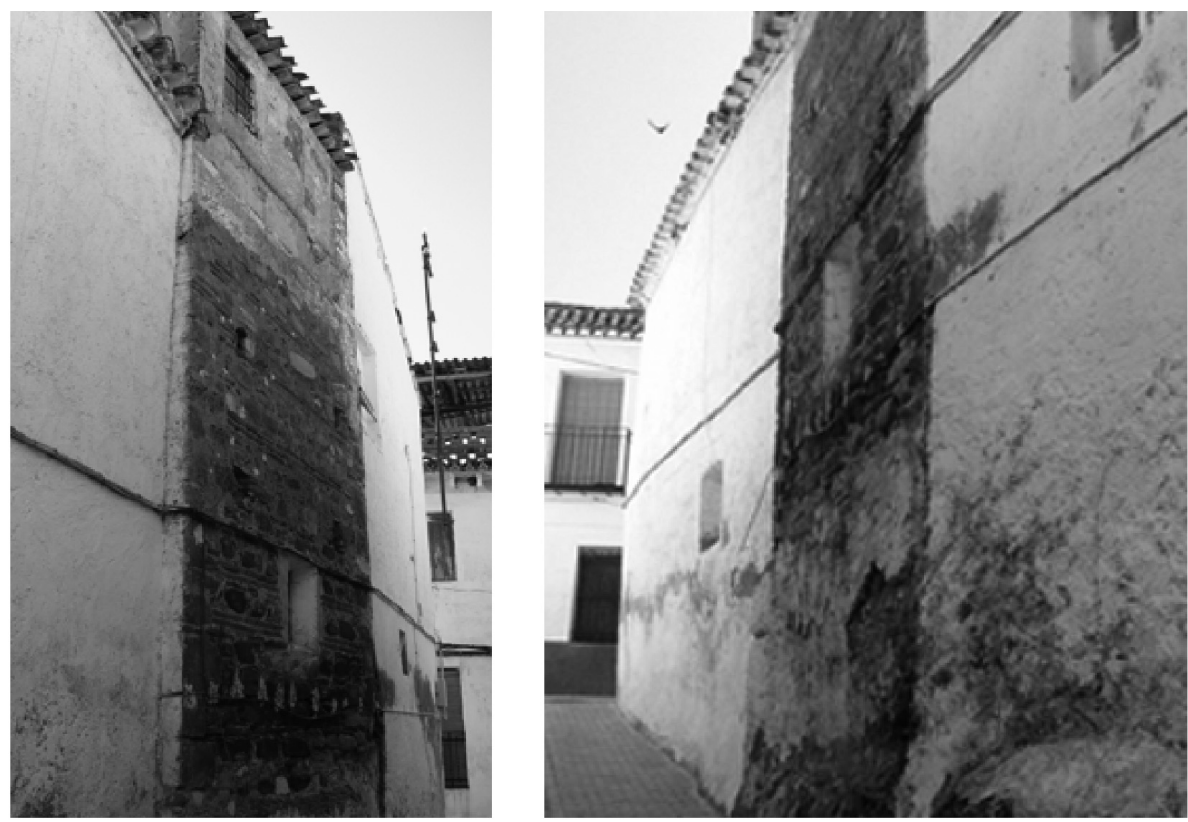

Vista de la torre de la rábita de Nigüelas.

En el documento de Apeo de los Bienes de Nigüelas de $1592^{53}$ también se dan noticias sobre estos centros religiosos en su folio 2 r, "un solar cercado de tapias que solía ser casa y sitio de rábita, que alinda por la parte de abajo con tierras del Capitán Alonso de Vilches, por parte de arriba con tierras y árboles de Antonio Treviño y con el camino y acequia que baja a las heredades de la orilla del barranco, y por otra parte el barranco del río, y tiene 1 moral pequeño y 1 ciruelo". En el folio 22r se cita "un sitio de iglesia vieja [mezquita] frontero del aljibe del agua, que por la parte del aljibe alinda con la calle y con el acequia que va a dar al lugar al Ramin, por la parte de arriba con una calleja angosta que pasa por entre el dicho solar de iglesia y casas de Pedro de Padilla, y por el poniente con una calle que desciende de la casa de Pablo de Vargas a dar a la dicha acequia y esta frontero la casa de Francisco Hernández el Mozo y del horno de la iglesia que está en medio del lugar".

En las escrituras de censo del lugar de Nigüelas ${ }^{54}$ hay una escritura que se hace ante Pedro de Navas, escribano público y notario de sus majestades, de 25 de julio de 1593 por la que el capitán Alonso de Vilches, alguacil, tomó de la

53. AHAGr. Sign. 291-F.

54. AHAGr. Sign. 232-F. 


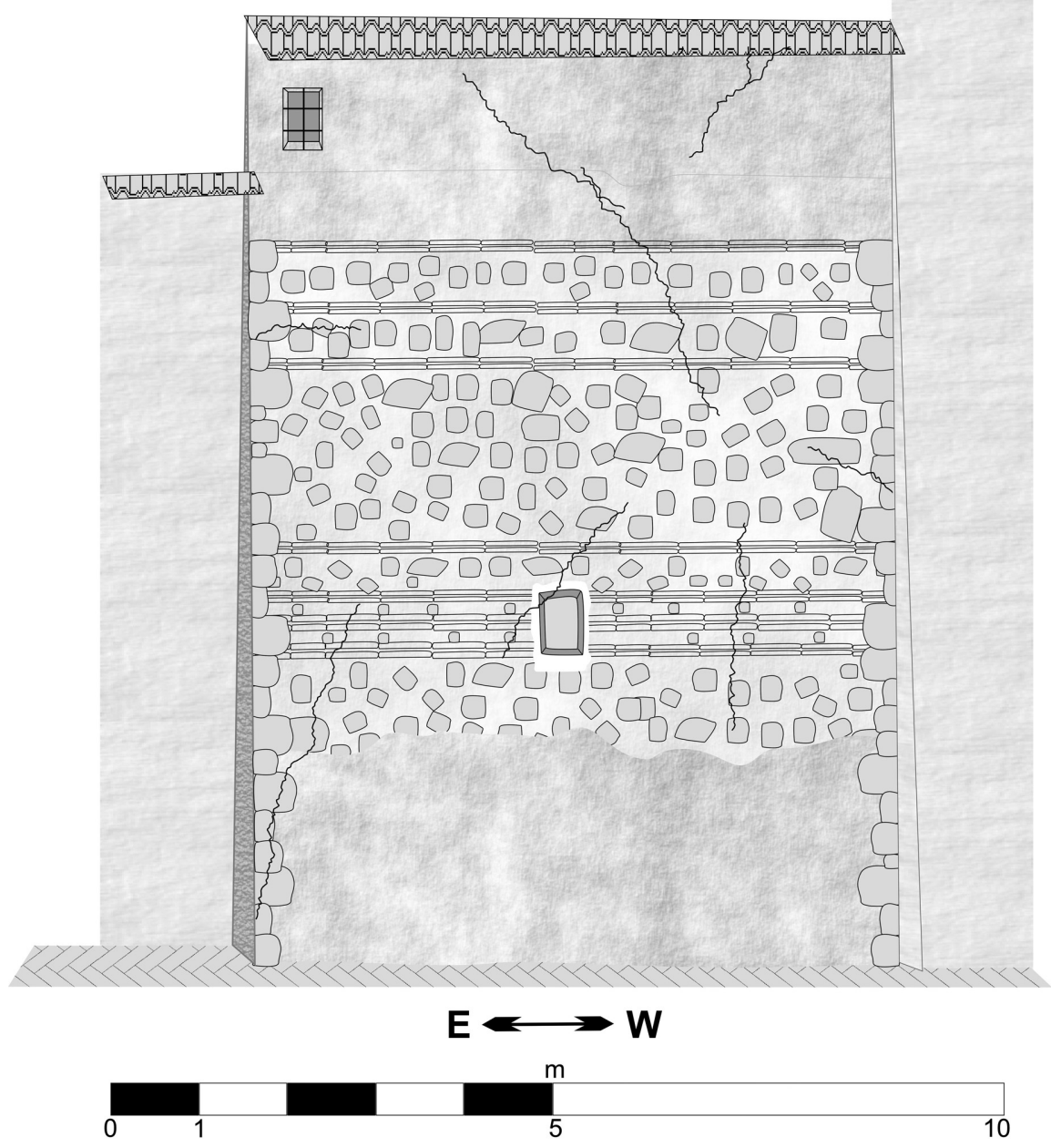

Alzado de la rábita de Nigüelas.

iglesia de Nigüelas a censo perpetuo de 30 reales, "2 casas una de ella medio caída, linderos con casa de Juan de la Paz, viuda, la Calle Real y la de Acequias que va a Dúrcal, y la otra que es una casilla pequeña que está en una rābitilla, con Benito García y dos acequias. Y un sitio de casa que solía ser de Pedro Ruiz con una calle en medio".

Luis Ramírez por escritura ante el mismo escribano en 6 de diciembre de 1542 tomó de dicha iglesia a censo perpetuo de 2 reales "dos pedazos de tierra 


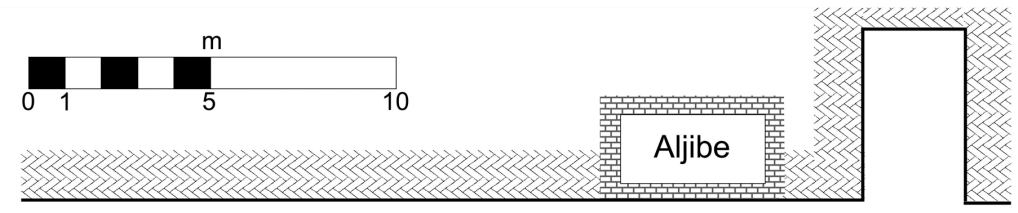

C/ Cruz

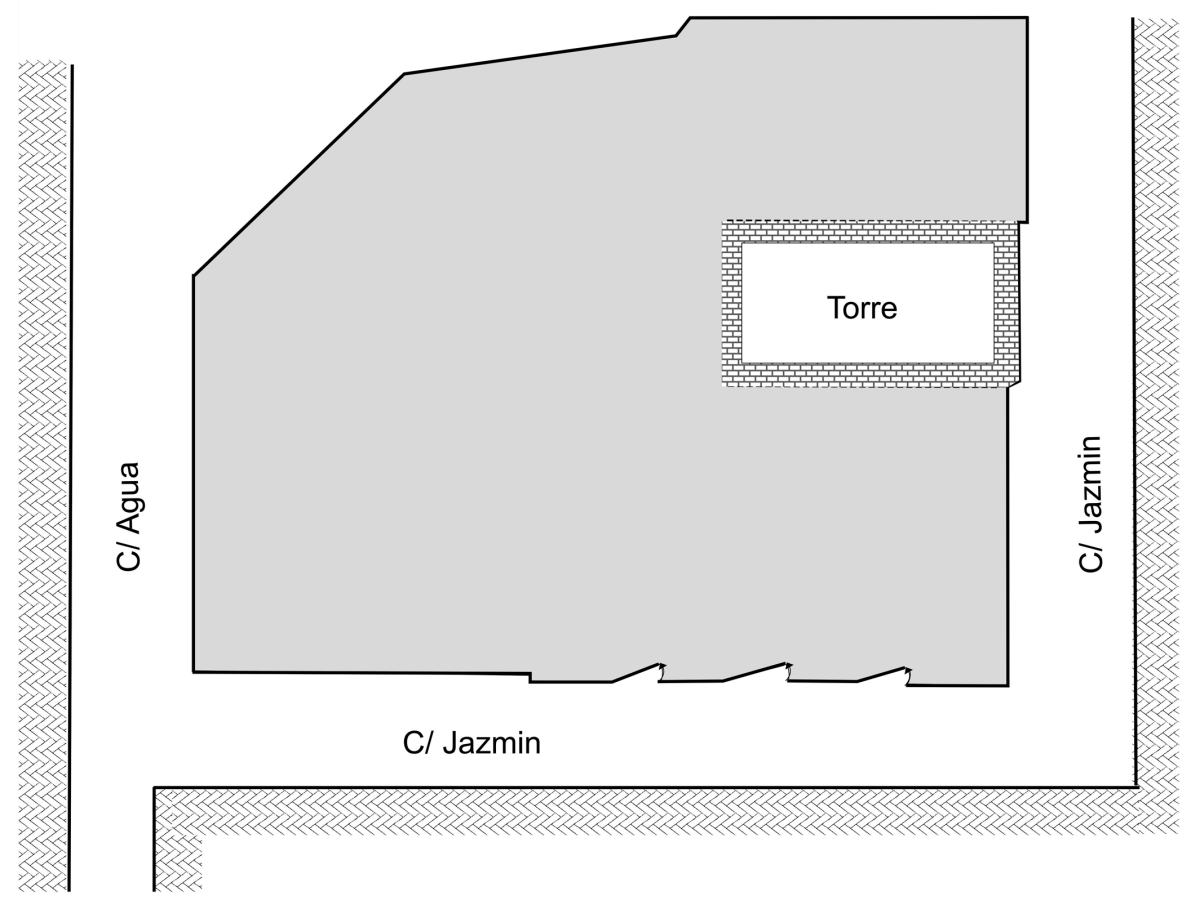

Planta de la rábita de Nigüelas.

de riego, ambas de tres marjales en el Pago del Rocán, en la puerta de la mezquita, que alinda el uno con haza de Hernando Arreoby y con el camino que va a Dúrcal, y el otro pedazo linda con haza de García el Lobo y con dicho camino".

En otra escritura que se hace ante Pedro de Córdoba, escribano público y notario de sus majestades en 17 de febrero de 1540, Juan Vílchez Clavijo y Diego Juanes "tomaron de la iglesia de Nigüelas a censo perpetuo de 182 maravedíes una porción de bienes, entre las que se encuentra una haza que labro Juan de Vilches en un solar que fue la rábita de Albarcoca, de 22 pies en largo y 22 pies en ancho, que alinda por todas partes con Calles Reales. Un solar en rábita que se llama Nazohira, con otro solarejo de casa de la dicha rábita que esta todo hecho un pedazo de tierra, en que puede haber un cuarto de marjal de tierra poco 

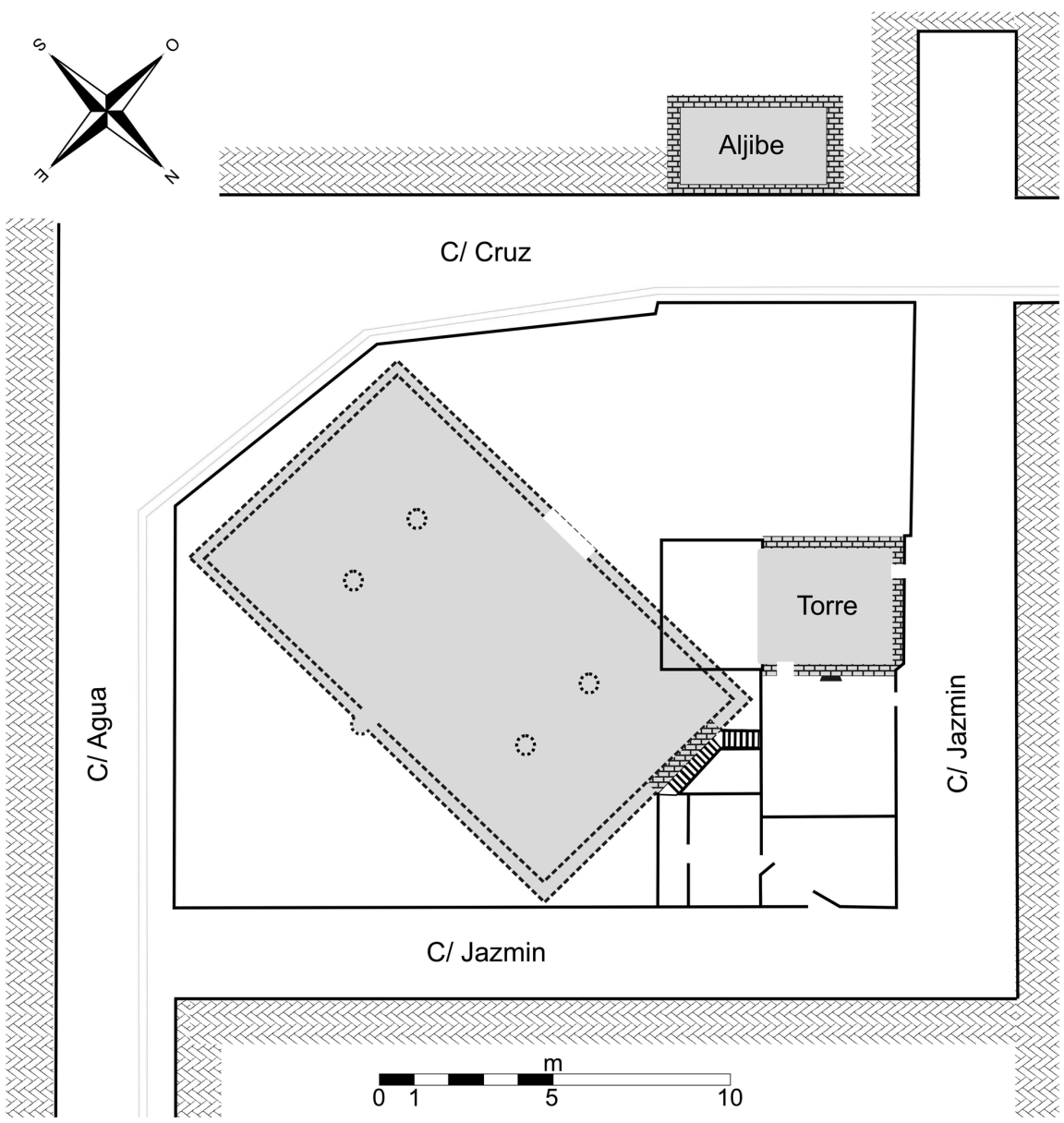

Planta idealizada de la mezquita de Nigüelas.

más o menos, el cual dicho solar está cercado de tapias ye lo tiene a censo Juan de Vilches. Alinda con huerta de Hernando de Mendoza, con huerta de Pedro el Harraz y con un camino. Otro pedazo de tierra en que puede haber medio marjal de tierra poco más o menos, de la rábita de Albinar con 19 posturas de morales nuevos, que alinda con haza y morales de Juan de Vilches, con huerta de Hernando el Guid, con huerta de Luis Arraz y con la Calle Real”. Más otra escritura que se hace ante Alonso Ruiz, escribano público y notario de sus majestades en 17 de agosto de 1547 por la que Hernando el Sordo "tomó de la iglesia de Nigüelas a censo perpetuo de 30 maravedíes, 2 pedazos de tierra de 2 marjales en la torre de la mezquita, que lindan con hazas del comprador, con huerta de Maldonado, con la de Juan Ozaybar y la cerca del lugar". 


\section{El Padul}

En el Libro Becerro en los censos correspondientes al Padul se relacionan los bienes que posee a censo Andrés Arrioli por los que paga medio real de censo cada año. Entre estos bienes se hallan "un solar de casa y una torrecilla en ella de rābita, que alinda con casa de los herederos de Martín de Vergara, con la Calle Real y con la casa de Luis Abiyaer". Pasó la escritura de censo ante el escribano del rey Alonso Ruiz. Su fecha en 20 de agosto de 1547. Está sacada en la contaduría y el registro en el escritorio de Pedro de Frías, escribano público de Granada.

Diego Farax Ortelano paga 1 real de censo cada año por "una rābita que se dice la Rābita del Horno, que alinda con las Calles Reales y con el horno de la iglesia". Pasó la escritura ante el escribano del rey Alonso Ruiz. Su fecha en 21 de agosto de 1547. Está sacada en la contaduría y en el registro del escritorio del escribano público de Granada Pedro de Frías con fecha 8 de julio de 1559.

\section{Pinos del Valle}

En el Libro Becerro se relaciona a Hernando Mateo que paga " 8 reales de censo cada un año por una casa y una rabitilla en el Barrio de Laujar de Pinos, que alinda con varias calles". Hay carta de censo en la contaduría que pasó ante el escribano del rey Alonso Ruiz. Su fecha en 3 de mayo de 1547.

Hernando de Cobaleda y María de Pisa su mujer pagan 11 reales de censo cada año por una rábita que está en el Barrio Alto de Pinos, que alinda con una acequia y con el camino que va a Motril. Pasó la carta del censo ante el escribano público de Granada Francisco de Córdoba. Su fecha en 13 de agosto de 1555.

Diego del Castillo el Besugo paga 2 reales de censo perpetuo en cada un año por una rábita de la iglesia de Pinos, en el Barrio Alto. Pasó la escritura ante el escribano público Francisco de Córdoba en 17 de febrero de 1558.

\section{Restábal}

En el Libro Becerro se relaciona que María Hernández paga 1,5 reales de censo perpetuo cada un año por una rábita que Luis Hernández su marido tomó a censo, que está en el Barrio Bajo de Restábal. “Alinda con tres calles Reales y está obligado el dicho Luis Hernández dentro de tres años de labrar 25 ducados de oro en la dicha rábita", los cuales comenzaron a correr desde el 15 de marzo de 1542. Está la escritura ante Pedro de Córdoba, escribano público de Granada que se hizo en el mismo día. No hay labrado nada hasta fin de 1554. Ha de labrar la susodicha y hacer reconocimiento. 
En las escrituras de censo de Restábal ${ }^{55}$ con Signatura 1534-F, en una escritura que se hace ante Pedro de Córdoba, escribano público y notario de sus majestades con fecha 19 de marzo de 1592 en la que Luis Hernández tomó de la iglesia de Restábal a censo perpetuo de 1,5 reales "una rābita en dicho pueblo en el Barrio del Mesón Alto, linde con tres calles". Otra escritura que se hace ante Alonso Ruiz, escribano público y notario de sus majestades en 19 de octubre de 1547, por la que Francisco Nieto "tomó de la iglesia de Restábal a censo perpetuo de 102 maravedís, un macaber por abrir y un solar de rábita, y un pedazo de tierra de 5 celemines de sembradura", cuyos linderos se expresan en dicha escritura, donde pueden verse.

\section{Saleres}

No se ha encontrado ninguno de estos centros religiosos en los documentos que se han estudiado hasta el momento.

\section{Tablate}

No se ha encontrado ninguno de estos centros religiosos en los documentos que se han estudiado hasta el momento.

\section{Talará}

No se ha encontrado ninguno de estos centros religiosos en los documentos que se han estudiado hasta el momento.

\section{RESUMEN}

La localización y situación en el entramado urbano de los edificios y estructuras que fueron mezquitas y rábitas y que existieron en el Valle de Lecrín ha sido gracias a las fuentes castellanas de que disponemos, ya que las fuentes árabes son escasas. Entre estas fuentes podemos destacar los bienes habices como una de las más valiosas. A través de estos documentos conoceremos las estructuras sociales, económicas y religiosas de la sociedad islámica en el Reino de Granada, recabando datos que escasamente han llegado hasta nosotros de este periodo.

55. AHAGr. Sign. 1534-F. 
En este trabajo se pretende dar a conocer las rábitas. De ellas sabemos gracias a los documentos referidos a una de las comarcas de la provincia de Granada, con personalidad propia, como es el Valle de Lecrín.

Palabras clave: rábita, mezquita, Reino de Granada, Valle de Lecrín, apeo, habices, iglesia, mudéjar, morisco.

\section{ABSTRACT}

The situation in the urban framework of the buildings and structures that were mosques and rābitas and that existed in the Lecrín Valley has been due to the Castilian sources that we have because the Arab sources are scarce. Among these sources, we can highlight the Land Allocation Goods like one of the most important. Through these documents, we will know the social, economic and religious structures of the Islamic society in the Kingdom of Granada, collecting data that scarcely have arrived to nowadays.

In this work we have tried to show the Rābitas concept. We know about these because in this days we can consults some documents related to one of the districts of the Granada province, with own personality, as it is the Lecrín Valley.

Key words: rábita, mosque, Kingdom of Granada, Lecrín Valley, Nigüelas, land registration books, land allocation, church, Mudéjar, Morisco. 